\title{
Clinical Characteristics and Long-Term Prognosis of Alport Syndrome: A Retrospective Single-Center Study
}

\section{Hea Min Jang, M.D. ${ }^{1}$ Hee Sun Baek, M.D. ${ }^{1}$ Sun-Hee Park, M.D. ${ }^{2}$ Yong-Lim Kim, M.D. ${ }^{2}$ Chan-Duck Kim, M.D. ${ }^{2}$ Hee-Yeon Jung, M.D. ${ }^{2}$ Jang-Hee Cho, M.D. ${ }^{2}$ Man Hoon Han, M.D. ${ }^{3}$ Yong Jin Kim, M.D. ${ }^{3}$ Min Hyun Cho, M.D.'}

Department of Pediatrics ${ }^{1}$, Internal Medicine ${ }^{2}$, Pathology ${ }^{3}$, Kyungpook National University, School of Medicine, Daegu, Republic of Korea

\author{
Corresponding author: \\ Min Hyun Cho, M.D. \\ Department of Pediatrics, Kyungpook \\ National University Hospital \\ 130 Dongdeok-ro, Jung-gu, Daegu 41944, \\ Republic of Korea \\ Tel: +82-53-200-5719 \\ Fax: +82-53-425-6683 \\ E-mail: chomh@knu.ac.kr \\ Received: 10 August 2020 \\ Revised: 17 September 2020 \\ Accepted: 4 October 2020
}

\begin{abstract}
This is an open-access article distributed under the terms of the Creative Commons Attribution Non-Commercial License (http:// creativecommons.org/licenses/by-nc/4.0/) which permits unrestricted non-commercial use, distribution, and reproduction in any medium, provided the original work is properly cited.
\end{abstract}

Purpose: Alport syndrome (AS) is one of the most common inherited renal diseases caused due to mutations of genes encoding specific proteins of the type IV collagen family, and its major clinical manifestations include progressive renal failure, sensorineural deafness, and ocular abnormalities. We investigated the clinical characteristics and long-term prognosis of AS in Korean pediatric and adult populations.

Methods: We conducted a retrospective review of medical records of 33 children and adults who had been diagnosed or treated with AS from 1985 to 2019.

Results: The mean age of the 33 patients diagnosed with AS was $16.2 \pm 13.6$ years, and the male-to-female ratio was 2:1. At the first visit, recurrent gross hematuria was the most common initial symptom. In 10 of 33 patients (30.3\%), sensorineural hearing loss (SNHL) was diagnosed, but none had ophthalmic problems. Moreover, 11 of 33 patients (33.3\%) had advanced to end-stage renal disease (ESRD), and a significant difference was observed in the age of the patients who progressed to ESRD based on the presence or absence of SNHL ( $P=0.035)$.

Conclusion: SNHL in AS can be an important prognostic factor for long-term deterioration of renal function. Further investigation is required to confirm the clinical course and the genetic characteristics of AS in Korea through prospective national cohort studies.

Key words: Alport syndrome, End-stage renal disease, Sensorineural hearing loss

\section{Introduction}

Alport syndrome (AS) is one of the most common inherited renal diseases caused due to mutations of genes encoding specific proteins of the type IV collagen family ${ }^{1)}$. The type IV collagen family is expressed in the basement membrane of the kidney as well as the ear and eye $\mathrm{e}^{2}$. The major features of AS are progressive renal failure, sensorineural deafness, and ocular abnormalities. Clinically, hematuria is the most common symptom of AS and generally manifests as microscopic or recurrent gross hematuria ${ }^{1-3)}$. Proteinuria is absent in the early stages, but it gradually increases with age, and all males with X-linked AS (XLAS) progress to end-stage renal disease (ESRD) $)^{1,2)}$.

AS has three genetic patterns. The majority, comprising approximately $80-85 \%$, show the X-linked dominant form caused due to mutations of the $C O L 4 A 5$ gene. Autosomal recessive or dominant forms caused due to mutation of the COL $4 A 3$ or $C O L 4 A 4$ gene have also been reported ${ }^{4-6}$. XLAS can 
be suspected when a young male has a severe course of illness. Untreated males with XLAS progress to ESRD before the age of 30 years and are frequently accompanied by hearing loss. However, females with XLAS exhibit various disease severities depending on the relative activities of the mutant and the normal X chromosome. Autosomal recessive AS (ARAS) should be suspected in young females who do not have a family history with typical clinical features and severe disease, such as ESRD and deafness ${ }^{2,7}$. The aims of this study were to identify the genetic and clinical characteristics of patients with AS in Korea and to identify the clinical indicators that can predict long-term prognosis

\section{Materials and methods}

\section{Study design and patients}

We retrospectively reviewed the medical records of 33 patients who had been diagnosed or treated with AS at our hospital from 1985 to 2019. AS was diagnosed through investigations such as family history, audiogram, ophthalmic examination, renal biopsy, and genetic study in patients with hematuria or AS family history. Clinical details such as age, sex, familial history, serum creatinine, urinalysis, and estimated glomerular filtration rate (eGFR) were collected. Renal biopsy was performed in 27 of the subjects, and particularly diffuse thickening and multilamellation of the glomerular basement membrane (GBM) on an electron microscope (EM) were used as diagnostic criteria. Genetic testing was performed in 18 of the subjects, and the conventional Sanger sequencing for the COL $4 A 5$ gene or next-generation sequencing (NGS) was performed. Hearing abnormality was defined as sensorineural hearing loss (SNHL) of moderate abnormality ( $41-55 \mathrm{~dB}$ ) in pure tone audiometry by audiogram. Ophthalmic abnormalities were characterized by anterior lenticonus and maculopathy, which are the characteristic of AS. Renal function was evaluated according to the eGFR value, and ESRD was defined when the eGFR value was less than $15 \mathrm{~mL} / \mathrm{min} / 1.73 \mathrm{~m}^{2}$.

\section{Statistical analysis}

The mean value of each category is reported as mean \pm SD. The Student's t-test or the Wilcoxon rank-sum test was used for analyzing continuous variables and nonparametric distributions. The Chi-square test and Fisher's exact test were used for analyzing categorical variables. The significance level was defined as $P<0.05$. All statistical analyses were performed using PASW Statistics ver. 18.0 (SPSS Inc., Chicago, Illinois, USA).

\section{Results}

The mean age of the 33 patients who first visited our hospital was $12.7 \pm 14.0$ years, and the male-to-female ratio was 2:1. Of the 33 patients, 26 (78.8\%) were diagnosed before the age of 18 years, with the mean age at diagnosis being $16.2 \pm$ 13.6 years. At the first visit, recurrent gross hematuria was the most common initial symptom (57.6\%), followed by proteinuria with persistent microscopic hematuria (PMH) (30.3\%) and PMH only (6.1\%) (Table 1).

For confirming the diagnosis, 27 (81.8\%) patients underwent renal biopsy, genetic tests were conducted in 18 patients (54.5\%), and 15 patients (45.5\%) underwent both. In the genetic tests, the conventional Sanger sequencing was performed in 14 patients (77.8\%) to identify COL $4 A 5$ gene mutation, and the remaining 4 patients underwent NGS. Based on the test results, COL4A5 gene mutation was confirmed in 7 patients (38.9\%), and 1 patient with COL $4 A 4$ gene mutation was confirmed through NGS. In the remaining patients, the COL $4 A 5$ gene mutation could not be confirmed by Sanger sequencing or the results of the mutation were unknown.

A total of 18 patients (54.5\%) had a family history of kidney disease, such as AS, chronic kidney disease, proteinuria, or microscopic hematuria. On the basis of the results of genetic tests and family history, the specific genetic patterns could be confirmed in only 9 patients, of whom 7 patients had an X-linked pattern, and 2 patients had an autosomal recessive genetic pattern.

Of the 33 patients, 11 (33.3\%) progressed to ESRD, with the mean age at ESRD diagnosis being $24.1 \pm 10.9$ years. The mean duration of progression to ESRD was $14.0 \pm 5.8$ years from the diagnosis of AS. The 8 patients (72.7\%) with ESRD underwent kidney transplantation, and 3 of them are on hemodialysis. None of the patients were diagnosed with ophthalmic problems, but there were 10 patients (30.3\%) with SNHL. The mean age at the diagnosis of SNHL was 
21.5 years (Table 1 and 2 ).

We divided all the patients with AS into 26 pediatric patients diagnosed at age $<18$ years and 7 adult patients diagnosed at age $\geq 18$ years. In pediatric patients, recurrent gross hematuria was the most common cause of the first visit, accounting for $73.1 \%$, whereas proteinuria with $\mathrm{PMH}$ was the most common in adults (71.4\%). In the diagnostic method, 23 of the 26 children (88.5\%) were biopsied and 17 (65.4\%) underwent genetic study, whereas in the adult group, 3 of 7 adults (42.9\%) were biopsied and only 1 (14.3 $\%)$ underwent genetic study. However, only 17 of the 23 children who underwent biopsy actually met the diagnostic criteria of AS and were subjected to more genetic tests than adults (Table 3 ).

When compared with the presence or absence of proteinuria as an initial symptom, no significant difference was detected in ESRD progression between the two groups. In contrast, SNHL was found at a significantly higher frequ- ency in the ESRD group ( $P=0.003$, Fisher's exact test) (Table 4). A significant difference was observed in the age of the patients who progressed to ESRD according to the presence or absence of SNHL $(P=0.035)$ (Fig. 1).

\section{Discussion}

AS is a hereditary kidney disease caused due to mutation of a specific protein of the type IV collagen family constituting the basement membrane. The disease is accompanied by progressive renal failure, hearing loss, and ocular abnormalities, and its prevalence has been estimated at 1 in 5,000 people in the United States or Europe. AS accounts for $0.5 \%$ of adults and $12.9 \%$ of children among all patients with $\mathrm{ESRD}^{7,8)}$. Most of the clinical symptoms in patients with AS manifest as recurrent gross hematuria and PMH before the age of 5 years. Proteinuria is uncommon at a

Table 1. General Characteristics and Laboratory Features of Patients with Alport Syndrome

\begin{tabular}{|c|c|c|c|c|}
\hline & Total & Male & Female & $P$ value \\
\hline Gender (n (\%)) & 33 & $22(66.7 \%)$ & $11(33.3 \%)$ & 0.479 \\
\hline Age at diagnosis, (n (\%)) & $16.2 \pm 13.6$ & $14.5 \pm 12.7$ & $19.7 \pm 15.2$ & 0.302 \\
\hline $0-18 y r$ & $26(78.8 \%)$ & 18 (81.8\%) & $8(72.7 \%)$ & 0.547 \\
\hline$\geq 18 \mathrm{yr}$ & $7(21.2 \%)$ & $4(18.2 \%)$ & $3(27.3 \%)$ & \\
\hline Age at first visit (yr) & $12.7 \pm 14.0$ & $11.6 \pm 11.8$ & $14.9 \pm 18.1$ & 0.593 \\
\hline Follow-up duration (yr) & $13.7 \pm 7.8$ & $12.7 \pm 6.7$ & $15.8 \pm 9.7$ & 0.289 \\
\hline Initial symptom, (n (\%)) & & & & 0.902 \\
\hline $\mathrm{RGH}$ & $19(57.6 \%)$ & 13 & 6 & \\
\hline $\mathrm{PU}+\mathrm{PMH}$ & $10(30.3 \%)$ & 7 & 3 & \\
\hline PMH only & $2(6.1 \%)$ & 1 & 1 & \\
\hline Others* & $2(6.1 \%)$ & 1 & 1 & \\
\hline Family history, (n (\%)) & $18(54.5 \%)$ & 9 & 9 & 0.026 \\
\hline Renal biopsy, (n (\%)) & $27(81.8 \%)$ & 19 & 8 & 0.338 \\
\hline Genetic study, (n (\%)) & $18(54.5 \%)$ & 13 & 5 & 0.458 \\
\hline Sanger sequencing & $14(77.8 \%)$ & 10 & 4 & \\
\hline NGS & $4(22.2 \%)$ & 3 & 1 & \\
\hline ESRD, (n (\%)) & $11(33.3 \%)$ & 8 & 3 & 0.602 \\
\hline Age at diagnosis of ESRD, (yr) & $24.1 \pm 10.9$ & $20.9 \pm 5.1$ & $32.6 \pm 18.9$ & 0.398 \\
\hline Duration from diagnosis to ESRD, (yr) & $13.95 \pm 5.82$ & $13.3 \pm 5.8$ & $15.8 \pm 6.6$ & 0.552 \\
\hline Renal replacement therapy, (n (\%)) & & & & 0.782 \\
\hline KT & $8(72.7 \%)$ & $6(75.0 \%)$ & $2(25.0 \%)$ & \\
\hline Hemodialysis & $3(27.3 \%)$ & $2(66.7 \%)$ & $1(33.3 \%)$ & \\
\hline SNHL, (n (\%)) & $10(30.3 \%)$ & $7(70.0 \%)$ & $3(30.0 \%)$ & 0.789 \\
\hline Age at diagnosis of SNHL, (yr) & $21.5 \pm 14.4$ & $20.0 \pm 16.4$ & $24.7 \pm 10.0$ & 0.665 \\
\hline
\end{tabular}

*Other includes seizure and familial history of Alport syndrome or other renal diseases.

Abbreviations: RGH, recurrent gross hematuria; PU, proteinuria; PMH, persistent microscopic hematuria; NGS, Next-generation sequencing; ESRD, endstage renal disease; KT, kidney transplantation; SNHL, sensorineural hearing loss. 
Table 2. Patient Characteristics

\begin{tabular}{|c|c|c|c|c|c|c|c|c|c|c|c|c|c|}
\hline $\begin{array}{l}\text { Case } \\
\text { No. }\end{array}$ & Sex & $\begin{array}{l}\text { Initial } \\
\text { symptom }\end{array}$ & $\begin{array}{l}\text { Onset } \\
\text { age } \\
(y r)\end{array}$ & $\begin{array}{l}\text { Renal } \\
\text { biopsy }\end{array}$ & $\begin{array}{l}\text { Genetic } \\
\text { study }\end{array}$ & Mutation & $\begin{array}{l}\text { Family } \\
\text { history }\end{array}$ & $\begin{array}{c}\text { F/U } \\
\text { duration } \\
(y r)\end{array}$ & RRT & SNHL & $\begin{array}{l}\text { Ocular } \\
\text { change }\end{array}$ & Last F/U symptom & $\begin{array}{l}\text { Duration } \\
\text { from initial } \\
\text { symptom to } \\
\text { ESRD (yr) }\end{array}$ \\
\hline 1 & M & $\mathrm{PU}+\mathrm{PMH}$ & 10.3 & Y & $\mathrm{Y}$ & COL4A5(-) & $\mathrm{N}$ & 8.75 & & $\mathrm{~N}$ & $\mathrm{~N}$ & Nephrotic PU+PMH & \\
\hline 2 & $\mathrm{~F}$ & $\mathrm{RGH}$ & 3.5 & Y & Y & COL4A5(-) & Y & 16.75 & & N & N & Non-nephrotic PU+PMH & \\
\hline 3 & M & $\mathrm{RGH}$ & 4.8 & Y & N & & N & 19.6 & KT & Y & N & ESRD & 16.9 \\
\hline 4 & M & $\mathrm{RGH}$ & 5.4 & Y & $\mathrm{N}$ & & $\mathrm{N}$ & 19 & $\mathrm{KT}$ & Y & $\mathrm{N}$ & ESRD & 12.9 \\
\hline 5 & M & $\mathrm{RGH}$ & 2.3 & Y & Y & COL4A5(-) & $\mathrm{N}$ & 20.3 & KT & Y & $\mathrm{N}$ & ESRD & 17.4 \\
\hline 6 & $\mathrm{~F}$ & $\mathrm{RGH}$ & 2.9 & Y & N & & N & 22.3 & & N & N & Non-nephrotic PU+PMH & \\
\hline 7 & M & $\mathrm{RGH}$ & 3.6 & Y & Y & $C O L 4 A 5(-)$ & Y & 15.3 & & $\mathrm{~N}$ & $\mathrm{~N}$ & Non-nephrotic PU+PMH & \\
\hline 8 & M & $\mathrm{RGH}$ & 13.2 & Y & Y & COL4A5(-) & Y & 9.6 & & N & N & Non-nephrotic PU+PMH & \\
\hline 9 & $F$ & $\mathrm{RGH}$ & 3.4 & Y & Y & COL4A5(c.796C>T) & N & 13.1 & & N & N & $\mathrm{RGH}$ & \\
\hline 10 & M & $\mathrm{PU}+\mathrm{PMH}$ & 11.3 & Y & Y & COL4A5(-) & N & 10.5 & & N & N & Non-nephrotic PU+PMH & \\
\hline 11 & M & $\mathrm{RGH}$ & 2.2 & Y & Y & COL4A5(c.2600dupT) & N & 9.0 & & N & N & Nephrotic PU+PMH & \\
\hline 12 & $\mathrm{~F}$ & $\mathrm{RGH}$ & 5.2 & Y & Y & COL4A5(-) & Y & 2.0 & & N & N & Nephrotic PU+PMH & \\
\hline 13 & M & PMH only & 2.6 & Y & N & & Y & 3.7 & & N & N & Non-nephrotic PU+PMH & \\
\hline 14 & M & $\mathrm{RGH}$ & 6.4 & Y & $\mathrm{N}$ & & $\mathrm{N}$ & 17.8 & $\mathrm{KT}$ & $\mathrm{N}$ & $\mathrm{N}$ & ESRD & 21.9 \\
\hline 15 & M & $\mathrm{PU}+\mathrm{PMH}$ & 12.1 & Y & Y & COL4A5(c.703C>T) & N & 8.5 & & Y & N & Nephrotic PU+PMH & \\
\hline 16 & $\mathrm{~F}$ & RGH & 2.8 & N & Y & COL4A5(c.3293G>T) & Y & 1.5 & & N & N & Non-nephrotic PU+PMH & \\
\hline 17 & $\mathrm{~F}$ & RGH & 2.4 & Y & N & & Y & 33.8 & KT & Y & N & ESRD & 17.5 \\
\hline 18 & M & $\mathrm{PU}+\mathrm{PMH}$ & 10.5 & Y & Y & $\begin{array}{l}\text { COL4A5(Gly1057Glu } \\
\text { +Gly1442Cys) }\end{array}$ & $\mathrm{N}$ & 20.3 & $\mathrm{KT}$ & Y & $\mathrm{N}$ & ESRD & 20.2 \\
\hline 19 & M & $\mathrm{RGH}$ & 11.6 & Y & $\mathrm{N}$ & & Y & 19.9 & $\mathrm{HD}$ & N & N & ESRD & 14.2 \\
\hline 20 & M & $\mathrm{RGH}$ & 1.8 & $\mathrm{~N}$ & Y & $\begin{array}{c}\text { COL4A5(c.3297G }>A \\
\text { c.4287delC) }\end{array}$ & Y & 2.3 & & $\mathrm{~N}$ & $\mathrm{~N}$ & Non-nephrotic PU+PMH & \\
\hline 21 & M & $\mathrm{RGH}$ & 10.7 & Y & $\mathrm{N}$ & & Y & 6.0 & & $\mathrm{~N}$ & $\mathrm{~N}$ & Non-nephrotic PU & \\
\hline 22 & M & $\mathrm{RGH}$ & 3.8 & N & Y & $\operatorname{COL} 4 A 5(c .465 G>A)$ & Y & 0.1 & & N & N & Non-nephrotic PU+PMH & \\
\hline 23 & M & $\mathrm{RGH}$ & 7.6 & Y & Y & $\begin{array}{c}\text { COL4A5 } \\
\text { (c.1580_1582del) }\end{array}$ & Y & 21.3 & & $\mathrm{~N}$ & N & Nephrotic PU+PMH & \\
\hline 24 & M & $\mathrm{RGH}$ & 1.7 & Y & Y & COL4A5(-) & N & 21.8 & $H D$ & Y & $\mathrm{N}$ & ESRD & 12.1 \\
\hline 25 & $\mathrm{~F}$ & PMH only & 2.0 & Y & Y & COL4A5(-) & Y & 28.4 & $H D$ & Y & N & ESRD & 21.4 \\
\hline 26 & $\mathrm{~F}$ & $\mathrm{PU}+\mathrm{PMH}$ & 15.5 & Y & $\mathrm{N}$ & & Y & 10.9 & & Y & N & Nephrotic PU+PMH & \\
\hline 27 & M & Others & 18.3 & N & N & & Y & 7 & KT & N & N & ESRD & 11.0 \\
\hline 28 & $\mathrm{~F}$ & Others & 46.5 & N & N & & Y & 15.3 & & N & N & PMH only & \\
\hline 29 & $\mathrm{~F}$ & $\mathrm{PU}+\mathrm{PMH}$ & 33.8 & N & N & & Y & 15.1 & & N & N & Non-nephrotic PU+PMH & \\
\hline 30 & M & $\mathrm{PU}+\mathrm{PMH}$ & 43.8 & Y & N & & N & 13.2 & & Y & N & Nephrotic PU+PMH & \\
\hline 31 & M & $\mathrm{PU}+\mathrm{PMH}$ & 33.2 & Y & N & & N & 15.3 & & N & N & Non-nephrotic PU+PMH & \\
\hline 32 & M & $\mathrm{PU}+\mathrm{PMH}$ & 37.7 & Y & Y & COL4A5(-) & N & 10.3 & & N & N & Non-nephrotic PU+PMH & \\
\hline 33 & $\mathrm{~F}$ & $\mathrm{PU}+\mathrm{PMH}$ & 45.7 & Y & $\mathrm{N}$ & & Y & 14.9 & KT & $\mathrm{N}$ & $\mathrm{N}$ & ESRD & 8.7 \\
\hline
\end{tabular}

Abbreviations: $\mathrm{RGH}$, recurrent gross hematuria; $\mathrm{PU}$, proteinuria; $\mathrm{PMH}$, persistent microscopic hematuria; F/U, follow up; RRT, renal replacement therapy; $\mathrm{SNHL}$, sensorineural hearing loss; ESRD, end-stage renal disease; KT, kidney transplantation; HD, hemodialysis.

young age, but it gradually increases with age ${ }^{5,7,8)}$. In our study, the male-to-female ratio was 2:1, and 26 patients (78.8\%) visited the hospital before the age of 18 years. At the first visit, recurrent gross hematuria was the most common initial symptom (57.6\%). When the symptoms were divided into hematuria and proteinuria, hematuria was observed in all patients, whereas proteinuria was found in only $33.3 \%$ of the patients. Jais et al. reported that $75.2 \%$ of patients with AS in Europe had proteinuria and 95\% had hematuria, ${ }^{9,10}$. In Japan, Yamamura et al. reported proteinuria in $72.6 \%$ and hematuria in $97.9 \%$ of patients ${ }^{11}$. Furthermore, Chugh et al. reported proteinuria and hematuria prevalence rates 
Table 3. Comparison of General Characteristics and Laboratory Features according to the Age of Diagnosis of Alport Syndrome

\begin{tabular}{lccc}
\hline & $<18(\mathrm{n}=26)$ & $\geq 18(\mathrm{n}=7)$ & $P$ value \\
\hline Gender, $(\mathrm{n}(\%))$ & & & 0.661 \\
Female & $8(30.8 \%)$ & $3(42.9 \%)$ & \\
Male & $18(69.2 \%)$ & $4(57.1 \%)$ & \\
Family history, $(\mathrm{n}(\%))$ & $14(53.8 \%)$ & $4(57.1 \%)$ & 0.876 \\
Initial symptom, (n (\%)) & & & 0.108 \\
RGH & $19(73.1 \%)$ & 0 & \\
PU+PMH & $5(19.2 \%)$ & $5(71.4 \%)$ & \\
PMH only & $2(7.7 \%)$ & 0 & \\
Others & 0 & $2(28.6 \%)$ & \\
Renal biopsy, (n (\%)) & $23(88.5 \%)$ & $4(57.1 \%)$ & 0.057 \\
Genetic study, (n (\%)) & $17(65.4 \%)$ & $1(14.3 \%)$ & 0.052 \\
Sanger sequencing & $13(76.5 \%)$ & $1(100 \%)$ & \\
NGS & $4(23.5 \%)$ & $0(0 \%)$ & \\
Rate of diagnosis & & & \\
Biopsy & $17 / 23$ & $3 / 4$ & \\
Genetic study & $8 / 17$ & $1 / 1$ & \\
Others* & 4 & 4 & 0.763 \\
ESRD, (n (\%)) & $9(34.6 \%)$ & $2(28.6 \%)$ & \\
SNHL, (n (\%)) & $9(34.6 \%)$ & $1(14.3 \%)$ & 0.299 \\
\hline
\end{tabular}

${ }^{*}$ Other includes seizure and familial history of Alport syndrome or other renal disease.

Abbreviations: NGS, Next-generation sequencing; RGH, recurrent gross hematuria; PU, proteinuria; PMH, persistent microscopic hematuria; ESRD, end-stage renal disease; SNHL, sensorineural hearing loss.

Table 4. Association between ESRD and Clinical and Laboratory Findings in Patients with Alport Syndrome

\begin{tabular}{lccc}
\hline & $\begin{array}{c}\text { ESRD (-) } \\
(\mathrm{n}=22)\end{array}$ & $\begin{array}{c}\text { ESRD (+) } \\
(\mathrm{n}=11)\end{array}$ & P value \\
\hline Gender, (n (\%)) & & 0.602 \\
Female & $8(36.4 \%)$ & $3(27.3 \%)$ & \\
Male & $14(63.6 \%)$ & $8(72.7 \%)$ & \\
Age at diagnosis, (n (\%)) & & & 0.763 \\
0-18yr & $17(77.3 \%)$ & $9(81.8 \%)$ & \\
$\geq 18$ yr & $5(22.7 \%)$ & $2(18.2 \%)$ & \\
Initial symptom & & & 0.789 \\
Hematuria & $15(68.2 \%)$ & $8(72.7 \%)$ & \\
Proteinuria & $7(31.8 \%)$ & $3(27.3 \%)$ & \\
Initial eGFR & $115.5 \pm 46.7$ & $99.3 \pm 49.3$ & 0.021 \\
Initial UP/Cr & $1.7 \pm 2.1$ & $1.8 \pm 2.2$ & 0.527 \\
Family history, (n (\%)) & $13(59.1 \%)$ & $5(45.5 \%)$ & 0.458 \\
Age at diagnosis (yr) & $17.4 \pm 14.7$ & $13.9 \pm 11.4$ & 0.467 \\
SNHL, (n (\%)) & $3(13.6 \%)$ & $7(63.6 \%)$ & 0.003 \\
Age at diagnosis of SNHL (yr) & $26.3 \pm 23.5$ & $19.4 \pm 10.4$ & 0.663 \\
\hline
\end{tabular}

Abbreviations: ESRD, end-stage renal disease; SNHL, sensorineural hearing loss; eGFR, estimated glomerular filtration rate; UP/Cr, urine proteinu/ creatinine.

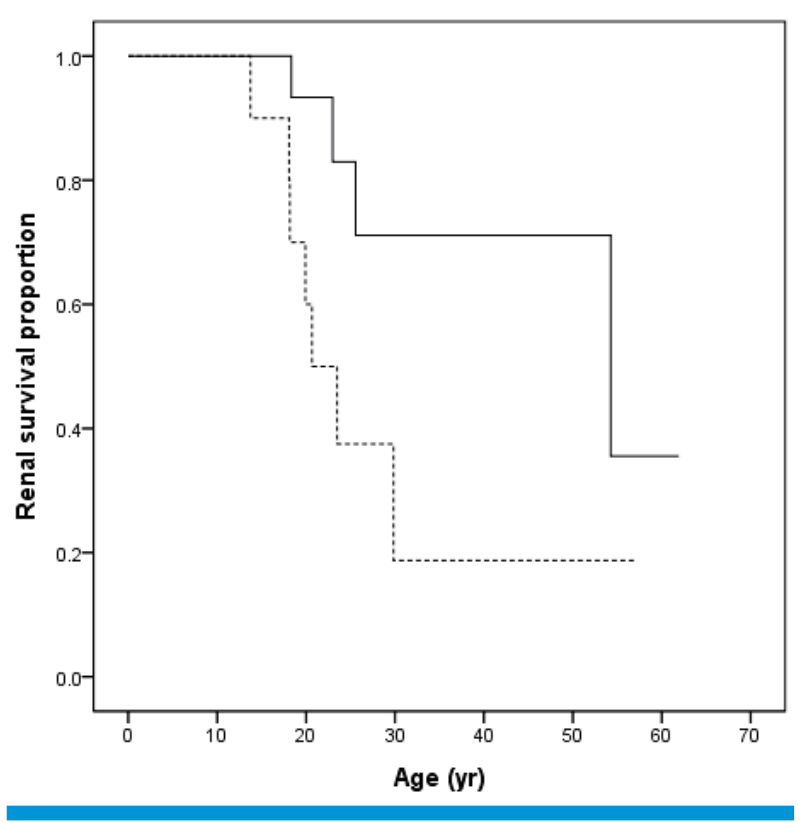

Fig. 1. Comparison of the time taken to proceed to ESRD according to the presence or absence of SNHL. Solid line indicates patients without sensorineural hearing loss $(n=23)$. Dots indicate patients with sensorineural hearing loss $(n=10)(P=0.035)$. Abbreviations: ESRD, end-stage renal disease; $S N H L$, sensorineural hearing loss.

of $31.7 \%$ and $96.8 \%$, respectively ${ }^{12)}$. Although there was a slight difference, hematuria was the most common in the majority of cases.

AS is diagnosed in patients with hematuria based on EM results of renal biopsy showing a multilamellation of GBM, and family history, SNHL, and ocular abnormalities are helpful for diagnosis ${ }^{2,3,7)}$. In our study, family history could be confirmed in $54.5 \%$ of the patients, and 27 patients ( 81.8 $\%)$ underwent renal biopsy, whereas only 18 patients $(24.2$ $\%)$ were genetically tested. Genetic study was performed in $65.4 \%$ of pediatric patients, whereas among the adults, only 1 patient (14.3\%) underwent genetic test. Moreover, among adults, the diagnosis was based on family history and clinical symptoms rather than renal biopsy or genetic testing. Inheritance could be confirmed in 9 patients based on family history and genetic study results, of whom 7 (77.8 \%) had XLAS, 2 (22.2\%) had ARAS confirmed, whereas ADAS was absent. In an earlier study of patients in China, Wei et al. reported that $89.7 \%$ of those with AS had XLAS and $10.3 \%$ had ARAS $^{13)}$.

In particular, the results of renal biopsy at a young age or in females can be ambiguous, which poses a limitation to diagnosis based on biopsy alone; moreover, the diagnosis 
becomes further complicated due to the difficulty in confirming the exact family history ${ }^{2,714)}$. Therefore, it is necessary to suspect AS if there is persistent hematuria of unknown etiology at a young age. In our study, only 17 of the 23 pediatric patients who underwent renal biopsy were diagnosed by biopsy, implying that genetic testing was performed in more children than adults. Furthermore, as genetic patterns cannot be discriminated based on only the abnormalities observed in EM findings, genetic study is essential to confirm the exact genetic pattern ${ }^{2)}$. Because it is known that the majority of AS is caused due to mutations of the COL $4 A 5$ gene, performing conventional Sanger sequencing of COL $4 A 5$ is cost-effective $e^{4)}$; however, NGS also has advantages as the possibility of mutation of the COL4A4 gene cannot be ruled out ${ }^{15}$. Moreover, the results of genetic testing are more important because various phenotypes can be displayed depending on the mutation position or the mutation type. Through NGS, it is easy to confirm large deletions and insertions in female patients, which are difficult to confirm by Sanger sequencing, and will help confirm inheritance in patients in whom it is difficult to confirm the pedigree. In countries with a large number of renal donations among relatives, such as Korea, it is believed that genetic testing for asymptomatic female carriers will help determine whether the donor has $\mathrm{AS}^{4}$. In the results of this study, it can be confirmed that the diagnosis of AS in adults is based on clinical symptoms, so that biopsy or genetic testing was rarely performed. Therefore, since genetic testing is important for identifying genetic patterns and predicting prognosis, it is essential to diagnose AS patients.

The prognosis for AS is poor, with $90 \%$ of males with XLAS and the majority of those with ARAS progressing to ESRD before age 30 years ${ }^{7,10,15)}$. No specific treatments are available till date, and recent studies have demonstrated that inhibition of the renin-angiotensin-aldosterone system using angiotensin-converting enzyme inhibitor or angiotensin receptor blocker slows the progression of the disease by reducing proteinuria. Dialysis or renal transplantation is performed when the patient reaches $\operatorname{ESRD}^{2,7)}$. Most of the patients with AS who progress to ESRD have a better prognosis than those with other kidney diseases. However, 2-5 $\%$ of transplant patients are likely to have graft failure due to post-transplant anti-GBM nephritis caused due to allo- antibodies to the donor kidney $\mathrm{GBM}^{7,16,17)}$. The factors associated with the prognosis of AS include gender, family history, age at onset, hearing loss, ocular abnormalities, and abnormalities in EM findings ${ }^{1,14}$. A study that analyzed the risk factors associated with long-term prognosis of AS in Korea reported hypertension, edema, proteinuria, and GFR at the time of diagnosis as the important factors in predicting prognosis ${ }^{1}$. Jais et al. reported that $78.3 \%$ of patients with XLAS progressed to ESRD, and $90 \%$ of patients progressed to ESRD before age 40 years. In addition, SNHL was reported in $28 \%$ of patients with XLAS in Europe, and ophthalmic complications accounted for $15 \%{ }^{9}$. On the other hand, Wei et al. reported that 47 of 126 (37.3\%) patients progressed to ESRD, 38.9\% of those in the XLAS group and $23.1 \%$ of those in the ARAS group had renal failure. SNHL was reported in $59.8 \%$ of the patients, with males being more significantly affected than females ${ }^{13,18}$. In the present study, 11 patients (33.3\%) had ESRD, and the mean age at the time of ESRD diagnosis was $24.1 \pm 10.9$ years. Moreover, there were $30.3 \%$ of patients with SNHL. In a previous study, Chugh et al. reported that there was no relationship between ESRD frequency and hearing loss and ophthalmic complications ${ }^{12)}$. However, in our study, SNHL was found to be more frequent in the ESRD group $(P=0.003)$ and there was a significant difference in the age of the patients who progressed to ESRD based on the presence or absence of SNHL ( $P=0.035)$. Jais et al. reported that hearing loss and proteinuria were significantly related to ESRD progression ${ }^{9}$, whereas no significant relationship was confirmed between proteinuria and ESRD in our study.

The present study has some limitations. Due to its retrospective design and being conducted in a single center, it was difficult to identify the exact inheritance pattern and the type of gene mutation because the diagnostic processes of the enrolled patients were not consistent and most physicians to treat adults with AS tend to not perform the genetic test for AS. However, by analyzing the clinical symptoms of pediatric and adult patients simultaneously, it was possible to analyze the diagnostic process and the long-term prognosis of AS in Korea. Moreover, our study confirmed that SNHL is an important prognostic factor for long-term deterioration of renal function. In addition, in order to confirm the correct inheritance related to the prognosis of AS, it is necessary to actively conduct genetic testing at 
diagnosis. Therefore, further research is needed to confirm the clinical course and the genetic characteristics of AS in Korea through prospective national cohort studies.

\section{Conflicts of interest}

No potential conflict of interest relevant to this article was reported.

\section{Ethics statement}

This study was approved by the Institutional Review Board of the Kyungpook National University Hospital (IRB No. 2020-07-054).

\section{ORCID IDs}

Hea Min Jang https://orcid.org/0000-0002-8231-2950

Hee Sun Baek https://orcid.org/0000-0003-0940-360X

Sun-Hee Park https://orcid.org/0000-0002-0953-3343

Yong-Lim Kim https://orcid.org/0000-0002-1344-3455

Chan-Duck Kim https://orcid.org/0000-0002-4648-0324

Hee-Yeon Jung https://orcid.org/0000-0003-0232-7202

Jang-Hee Cho https://orcid.org/0000-0002-7031-5214

Man Hoon Han https://orcid.org/0000-0001-8856-553X

Yong-Jin Kim https://orcid.org/0000-0002-9867-0752

Min Hyun Cho https://orcid.org/0000-0002-7965-7587

\section{References}

1. Byun JY, Baek SY, Lee YM, Kim JH, Lee JS, Kim PK, et al. Risk Factor's Affecting long-term Outcome of Alport syndrome. J Korean Soc Pediatr Nephrol 2001;5:164-75.

2. Kashtan CE, Michael AF. Alport syndrome. Kidney Int 1996;50: 1445-63.

3. Flinter FA. Bobrow M, Chantler C. Alport's syndrome or hereditary nephritis? Pediatr Nephrol 1987;1:438-40.
4. Cheong HI. Genetic diagnosis of Alport syndrome. Korean J Pediatr 2019;62:164-5.

5. Bekheirnia MR, Reed B, Gregory MC, McFann K, Shamshirsaz AA, Masoumi A, et al. Genotype-phenotype correlation in X-linked Alport syndrome. J Am Soc Nephrol 2010;21:876-83.

6. Kruegel J, Rubel D, Gross O. Alport syndrome--insights from basic and clinical research. Nat Rev Nephrol 2013;9:170-8.

7. Nozu K, Nakanishi K, Abe Y, Udagawa T, Okada S, Okamoto T, et al. A review of clinical characteristics and genetic backgrounds in Alport syndrome. Clin Exp Nephrol 2019;23:158-68.

8. Barker DF, Hostikka SL, Zhou J, Chow LT, Oliphant AR, Gerken SC, et al. Identification of mutations in the COL4A5 collagen gene in Alport syndrome. Science 1990;248:1224-7.

9. Jais JP, Knebelmann B, Giatras I, De Marchi M, Rizzoni G, Renieri A, et al. X-linked Alport syndrome: natural history in 195 families and genotype-phenotype correlations in males. J Am Soc Nephrol 2000;11:649-57.

10. Jais JP, Knebelmann B, Giatras I, De Marchi M, Rizzoni G, Renieri A, et al. X-linked Alport syndrome: natural history and genotypephenotype correlations in girls and women belonging to 195 families: a "European Community Alport Syndrome Concerted Action" study. J Am Soc Nephrol 2003;14:2603-10.

11. Yamamura T, Nozu K, Fu XJ, Nozu Y, Ye MJ, Shono A, et al. Natural History and Genotype-Phenotype Correlation in Female X-Linked Alport Syndrome. Kidney Int Rep 2017;2:850-5.

12. Chugh K, Sakhuja V, Agarwal A, Jha V, Joshi K, Datta B, et al. Hereditary nephritis (Alport's syndrome)-clinical profile and inheritance in 28 kindreds. Nephrol Dial Transplant 1993;8:690-5.

13. Wei G, Zhihong L, Huiping C, Caihong Z, Zhaohong C, Leishi L. Spectrum of clinical features and type IV collagen alpha-chain distribution in Chinese patients with Alport syndrome. Nephrol Dial Transplant 2006;21:3146-54.

14. Grunfeld JP. The clinical spectrum of hereditary nephritis. Kidney Int 1985;27:83-92.

15. Artuso R, Fallerini C, Dosa L, Scionti F, Clementi M, Garosi G, et al. Advances in Alport syndrome diagnosis using next-generation sequencing. Eur J Hum Genet 2012;20:50-7.

16. Kelly YP, Patil A, Wallis L, Murray S, Kant S, Kaballo MA, et al. Outcomes of kidney transplantation in Alport syndrome compared with other forms of renal disease. Ren Fail 2017;39:290-3.

17. Temme J, Kramer A, Jager KJ, Lange K, Peters F, Muller GA, et al. Outcomes of male patients with Alport syndrome undergoing renal replacement therapy. Clin J Am Soc Nephrol 2012;7:196976.

18. Wang F, Ding J, Guo S, Yang J. Phenotypic and genotypic features of Alport syndrome in Chinese children. Pediatr Nephrol 2002; 17:1013-20. 